\title{
TIPOS E CASOS: HABITAÇÃO DE GRANDE ESCALA NA AMÉRICA LATINA, UMA SELEÇÃO DE OBRAS E POSSIBILIDADES DE SUA AVALIAÇÃO CONTEMPORÂNEA
}

\section{Types And Cases: Large Scale Housing Blocks In Latin America, Selected Works And Possibilities Of Its Contemporary Evaluation}

\author{
Pedro Morais \\ Universidade Federal de Minas Gerais \\ pedromorais.arquiteto@gmail.com
}

\section{Resumo}

Esse artigo é parte da pesquisa de doutorado em desenvolvimento pelo autor, cujo tema são os grandes blocos de habitação coletiva vertical construídos na América Latina ao longo do século XX: suas origens, documentação das principais realizações, análise crítica de edifícios representativos e, por fim, uma tentativa de avaliar sua pertinência nas cidades atuais, apontando possíveis evoluções futuras. $O$ presente trabalho apresenta o recorte adotado na pesquisa a partir da caracterização tipológica que embasa a seleção dos edifícios objeto do estudo, que consistirá em estudo comparativo de casos múltiplos, e ainda algumas possibilidades da abordagem contemporânea da questão.

\section{Palavras-chave}

Arquitetura, Projeto Arquitetônico, Habitação, América Latina, Século XX, Verticalização

\begin{abstract}
This article is a part of the author's ongoing PhD's research studies concerning the vertical mass-scale housing projects built at Latin America along twentieth century: its origins, documentation of major accomplishments, critical analysis of key buildings, an attempt on prospecting their pertinence on contemporary cities and, by the end, an intent of pointing out possible future developments for the theme. The present article presents the proposed cutting of the research from the typological characterization that based the selection of the objects to be studied and to consist on a multiple case study comparison among paradigmatic examples of the focused building type, and also a few possibilities for a contemporary aproach of this subject.
\end{abstract}


Architecture, Architectural Design, Housing, Latin America, XXth Century

\section{Universo de Estudo}

O urbanismo moderno e a ideia de que as cidades carecem de planejamento são decorrências direta da Revolução Industrial. O advento da industrialização incita o afluxo de grandes contingentes de trabalhadores do campo para a cidade, em busca de trabalho, do novo e do futuro. É também este fator que promove o aumento exponencial das dimensões das aglomerações urbanas, a partir de uma dinâmica de forças ao mesmo tempo centrípetas e centrífugas, na qual os centros urbanos se tornam fortes polos de atração de atividades e por outro lado promovem a expansão física desmesurada do urbano sobre o seu entorno imediato e sobre o campo.

Conforme colocado de modo perspicaz por Philippe Panerai, é neste momento que as aglomerações urbanas sofrem uma transição de escala sem precedentes, fazendo com que um simples trevo rodoviário possa ocupar área equivalente a toda uma cidade do período pré-moderno.
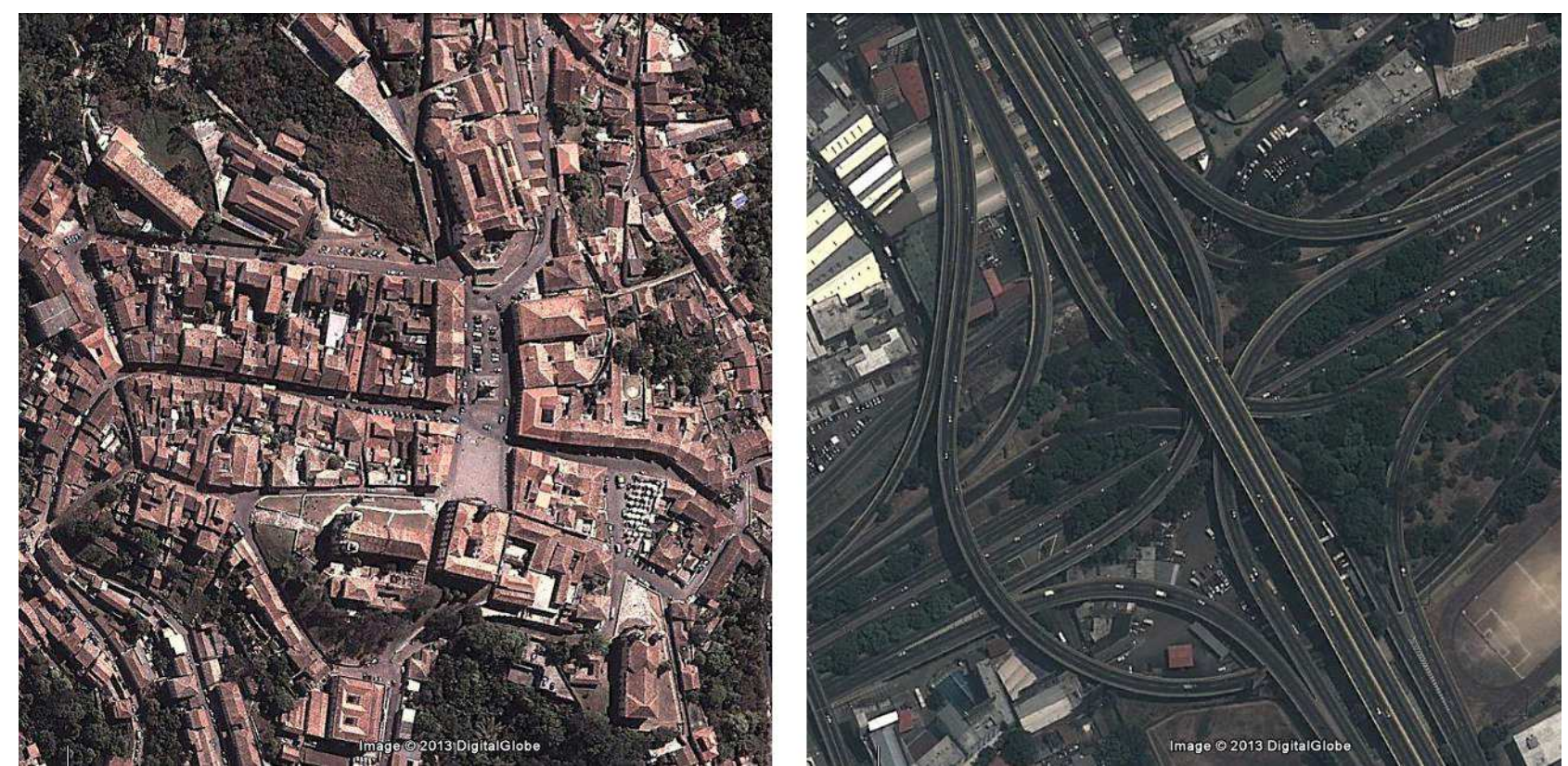

Figura 1: Na mesma escala, à esquerda a praça Tiradentes em Ouro Preto e à direita o nó viário em

Caracas conhecido como "La araña".

Fonte: Google Earth

Desde meados do século XIX, a necessidade de alocar a grande massa de trabalhadores adquire diversas configurações espaciais em locais distintos: as mietskasernen alemãs, os tenements estadunidenses e as favelas latinoamericanas 
são bons exemplos disso. Não por acaso, todas tem em comum as más condições de moradia que oferecem ao trabalhador, muitas vezes persistindo até os dias atuais.

No livro "Quando o moderno não era um estilo e sim uma causa", Anatole Kopp argumenta que o desejo de melhorar as condições da moradia operária na Europa arrasada pela guerra é a causa que mobiliza os arquitetos da vanguarda europeia a investigar novas possibilidades para a habitação urbana, percebendo tal fatia da sociedade como tendo se tornado uma recente clientela coletiva, que merecia a atenção da classe, antes dedicada apenas a atender as classes mais abastadas.

Em um primeiro momento, no qual o planejamento urbano começa a se estabelecer como disciplina na Europa, são importantes teorias como as de Patrick Abercrombie, Patrick Geddes, Robert Owen, Ebenezer Howard e Raymond Unwin na Inglaterra, Charles Fourier e Tony Garnier na França e Ildefons Cerdá e Arturo Soria $Y$ Mata na Espanha. Num segundo momento, no início do século XX, Friedrick Law Olmsted, Vaux e Burnham atuam nos EUA repensando a natureza e a cidade de modo particular. É relevante a passagem pela América Latina de urbanistas acadêmicos como Joseph Bouvard, Barry Parker, Augusto Guidini e Ernest Coxhead. No primeiro pós-guerra, destacam-se as ideias dos construtivistas e desurbanistas soviéticos, a construção dos Hoffe vienenses, a atuação de Walter Gropius, Ernst May e Ludwig Hilberseimer na Alemanha e de Le Corbusier e André Lurçat na França.

No contexto da América Latina, os estudos urbanos mais relevantes no que tange ao tema da pesquisa são as proposições de Jean-Claude Forestier, Antonio Bonet, Werner Hegemann, Wladimiro Acosta e Fermín Bereterbide na Argentina, o trabalho de Karl Brunner na Colômbia e Argentina, de Hannes Meyer no México e os projetos de Josep Lluis Sert e Paul Lester Wiener para diversas pontos do continente, além das contribuições seminais de figuras como Alfred Agache, Saturnino de Brito, Prestes Maia, Pereira Passos e Aarão Reis no Brasil, Maurice Rotival na Venezuela, Maurício Cravotto no Uruguai e Pedro Martinez Inclán em Cuba, profissionais cuja atuação é abordada por diversos autores no livro Urbanismo na América do Sul: circulação de ideias e constituição do campo 1920-1960 e também em Urbanismo no Brasil 1895-1965, organizado por Maria Cristina da Silva Leme.

Relevantes para a postulação do modelo de habitação em estudo, tais teorias e realizações atuaram diretamente na configuração das grandes metrópoles latinoamericanas. Sendo a urbanização destes núcleos urbanos bem mais recente que na Europa, o urbanismo moderno determinou em grande medida a fisionomia de cidades como São Paulo, Belo Horizonte, Caracas, Bogotá, Havana, Buenos Aires ou 
cidade do México, mesmo que o traçado de tais cidades seja originalmente de concepção acadêmica ou positivista.

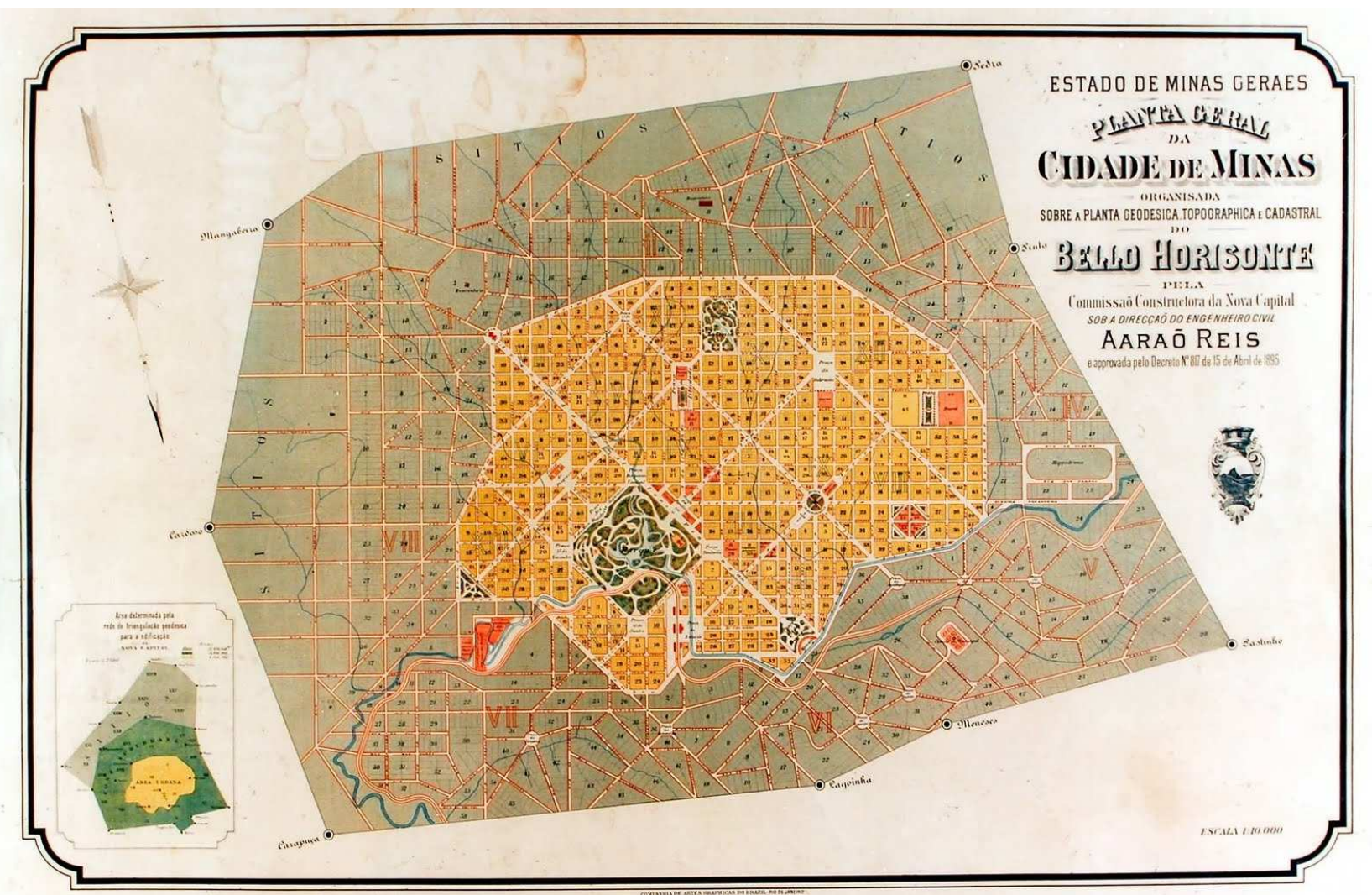

Figura 2: Planta da cidade de Belo Horizonte, de autoria do engenheiro Aarão Reis, 1895 Fonte: http://commons.wikimedia.org/wiki/File:Planta_BH.jpg

\section{Algumas questões pertinentes}

Do ponto de vista histórico, a proposição e execução de grandes edifícios de habitação coletiva na América Latina tem grande relação com as teorias e realizações sobre o tema desenvolvidos na Europa, URSS e América do Norte e a circulação mundial de ideias desde o século XIX. Por outro lado, envolve uma série de fatores (políticos, culturais, sociais, históricos, climáticos, etc) distintos daqueles encontrados no hemisfério norte. Nesse sentido, faz-se importante uma revisão crítica dos escritos sobre o tema, no sentido de identificar a justa medida e extensão das semelhanças e diferenças no desenvolvimento do tema aqui e lá, as trocas ocorridas entre arquitetos locais e estrangeiros e os motivos que ensejaram a adaptação e adoção, em vários pontos do continente, de um modelo originalmente proposto com a intenção de melhorar as condições de higiene das cidades tradicionais europeias por um lado e reconstruir estas mesmas cidades após sua destruição pelas duas grandes guerras. 
A antes iniludível noção de "influência" passou, pelo menos nos campos historiográficos mais sofisticados, a uma vida melhor. Graças a pesquisas que mostraram a força da circulação das ideias na modernidade, as noções de centro e periferia conjugam-se no plural, deixando para trás o tempo em que, para celebrar ou injuriar as vanguardas, eram tomadas como versões, mais ou menos bem-sucedidas, mais ou menos degradadas, os seus modelos de referência. (...) A ideia de um conjunto de valores originais, que devia ser estendida e aplicada, foi um componente essencial no desenvolvimento mundial do modernismo, tanto nos exemplos centrais como (sic) nos periféricos. (GORELIK, 2005)

Pela extensão de material publicado e até mesmo pela postura pública do arquiteto, não é incomum que a historiografia da arquitetura atribua a Le Corbusier mérito quase exclusivo na postulação da tipologia de habitação em grandes blocos.

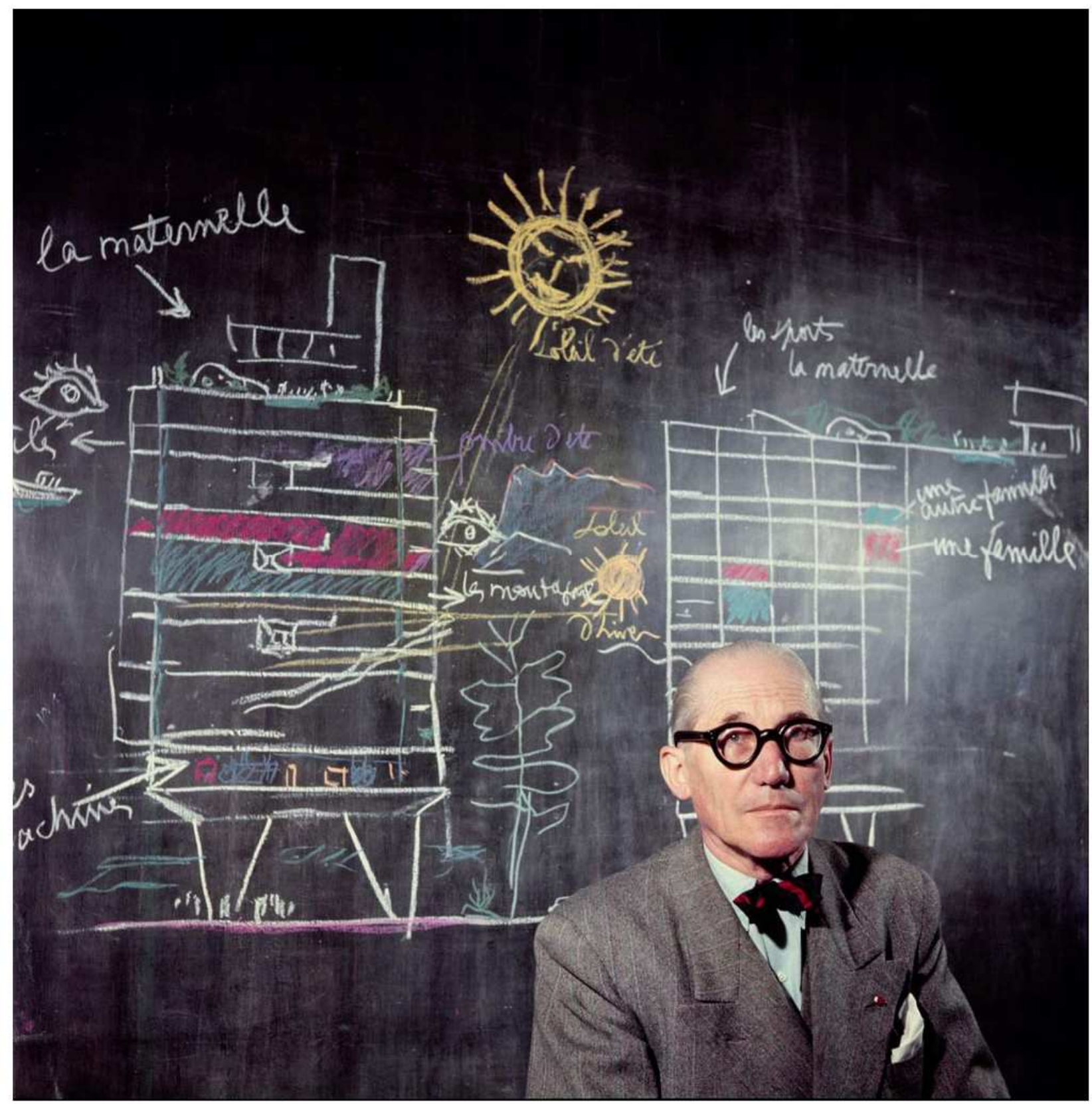


Figura 3: Le Corbusier e L'Unité d'habitation, fotografado por Willy Rizzo Fonte: www.fondationlecorbusier.fr

Entretanto, ao menos desde finais do século XIX, a questão do planejamento do espaço urbano e do estabelecimento de novas formas de habitação de massa vem sendo estudada e teorizada por diversos autores, em várias partes do mundo. Um bom exemplo é o trabalho do urbanista alemão Ludwig Hilberseimer, publicado de modo extensivo em seu livro Großstadtarchitektur, de 1928.

Ao contrário das buscas por aplicação imediata que caracterizaram as proposições do mestre franco-suíço, as postulações de Hilberseimer tem caráter bem mais científico, como ele mesmo menciona em seu último livro Un'idea di piano, de 1963. Seu estudo de 1928 para a arquitetura da grande cidade apresenta considerável evolução teórica à proposta corbusiana da Ville Contemporaine pour trois millions d'habitants de 1922, no qual o zoneamento de moradias, comércio, escritórios e lazer localizavam-se em setores urbanos distintos.

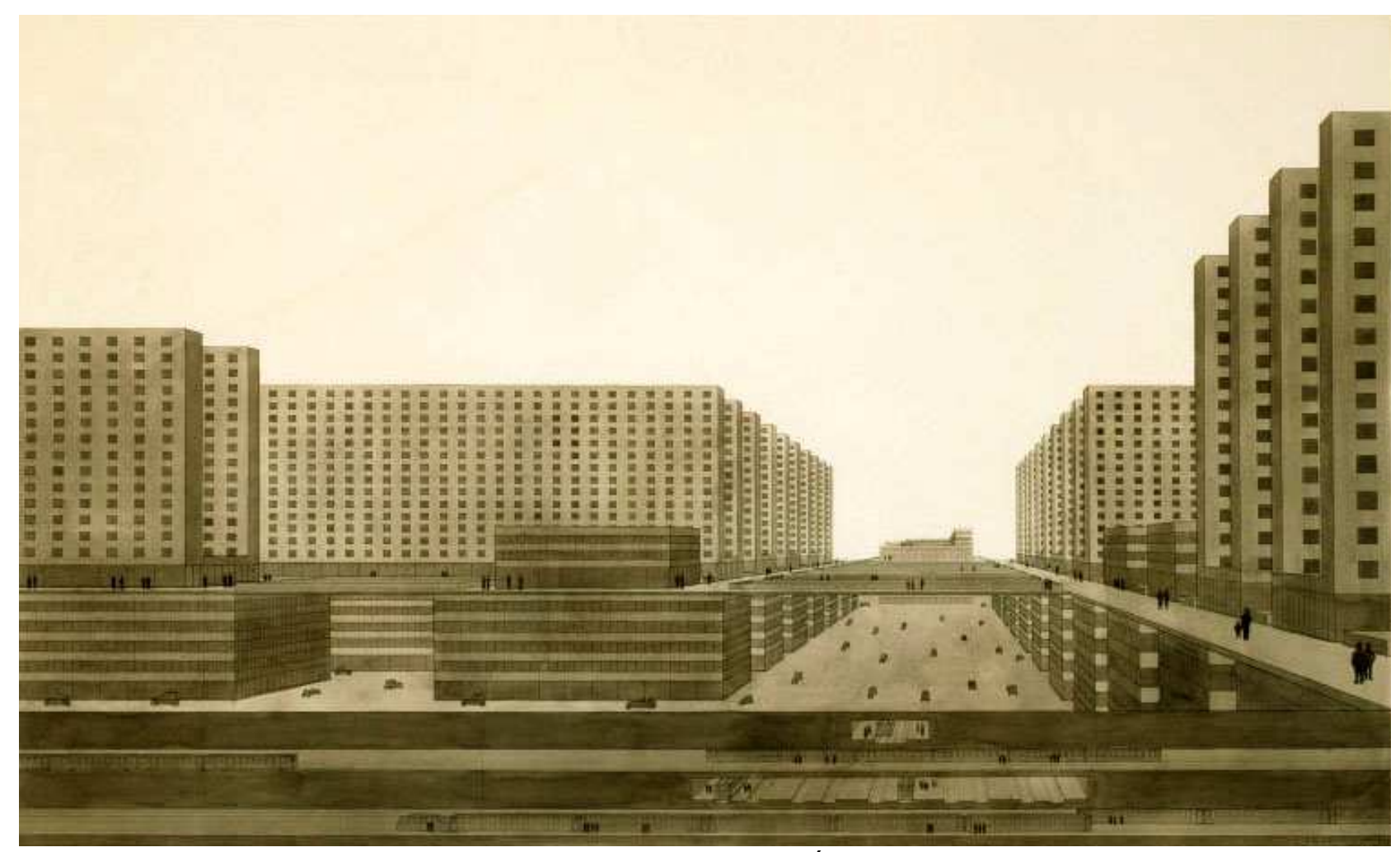

Figura 4: Hochhausstadt, A cidade vertical teórica de Ludwig Hilberseimer

Fonte: Großstadtarchitektur, 1928

Embora aparentemente rígidas em vista de seu caráter eminentemente teórico, na proposta do alemão, a setorização da cidade se dava em estratos horizontais sobrepostos: nos subsolos o metrô como transporte de massa, no nível do solo, o trânsito de veículos junto ao qual seriam localizados os usos comerciais e de 
serviços e acima destes, a cidade residencial e a livre circulação de pedestres. A sobreposição de atividades ali apresentada tem caráter bem mais próximo da diversidade e interpenetração de usos e atividades caracterizadora do chamado sinecismo, qualidade urbana defendida por Jane Jacobs em seus estudos urbanos e valorizada por autores contemporâneos como Edward Soja e Michael Storper dentro do grupo de estudos regionais de Los Angeles.

Leituras preliminares apontam insuspeitada relação entre o tema em estudo e o surpreendente resultado do concurso para o Palácio dos Sovietes, divulgado em 1932. Tal acontecimento faria com que o 40 CIAM, a realizar-se em Moscou em 1933, fosse adiado um ano e realizado na mítica viagem a bordo do Patris II de Marselha a Atenas. Daria origem assim à Carta de Atenas, bíblia do movimento moderno desde sua publicação por Corbusier em 1943. Pode-se especular que, caso tivéssemos assistido à URSS tornar-se a meca dos arquitetos de vanguarda, ao invés do recrudescimento stalinista que de fato ocorreu, quiçá hoje teríamos uma "Carta de Moscou", o trânsito de arquitetos europeus nas Américas de então seria provavelmente menor, o que definitivamente interfere no tema que pretende-se discutir. A lembrança das primeiras experiências russas, no entanto, permaneceu.

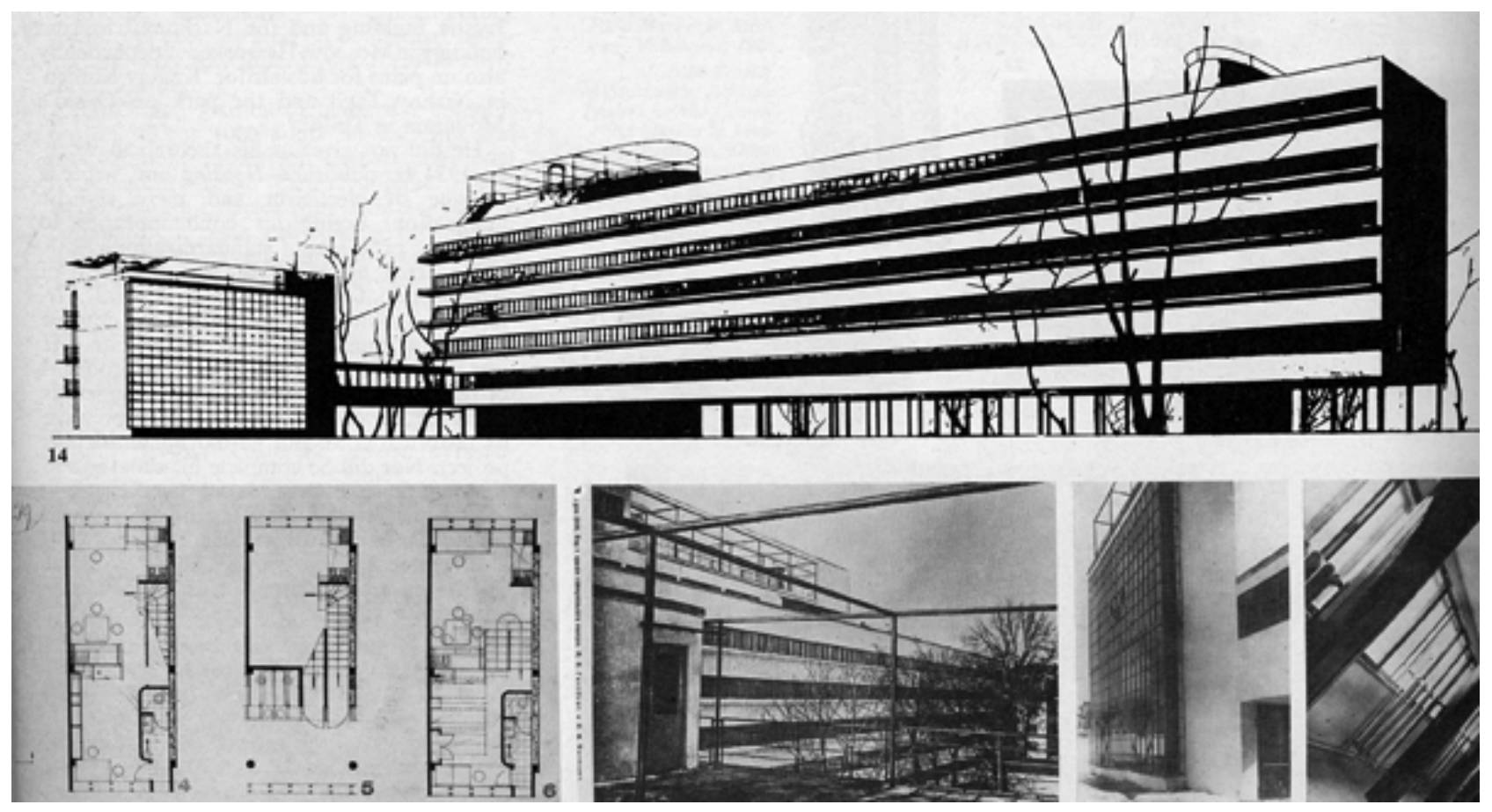

Figura 5: Edifício Narkomfin, em Moscou, projeto de Moisei Ginzburg e Ignati Milinis Fonte: http://wiki.ead.pucv.cl/index.php/EdificiodelNarkomfindeM.Ginzburg-I.Milinis/SebastianArancibiaC. 
Gerard Monnier alerta para um erro corrente da historiografia acerca dos grandes edifícios de habitação: atenção excessiva tem sido dedicada aos elementos estilísticos do tipo em detrimento do entendimento da invenção tipológica em si, tão cara aos praticantes e teóricos da arquitetura e do urbanismo da primeira metade do século XX. A oportunidade da divulgação de tais edifícios e sua consequente inserção na história da arquitetura viria defini-los como um um estilo, o que fez com que mais atenção tenha sido dedicada aos elementos de tal estilo (teto-jardim, pilotis, panos de vidro etc) do que à tipologia nova que ali se estabeleceu. (MONNIER: 2002)

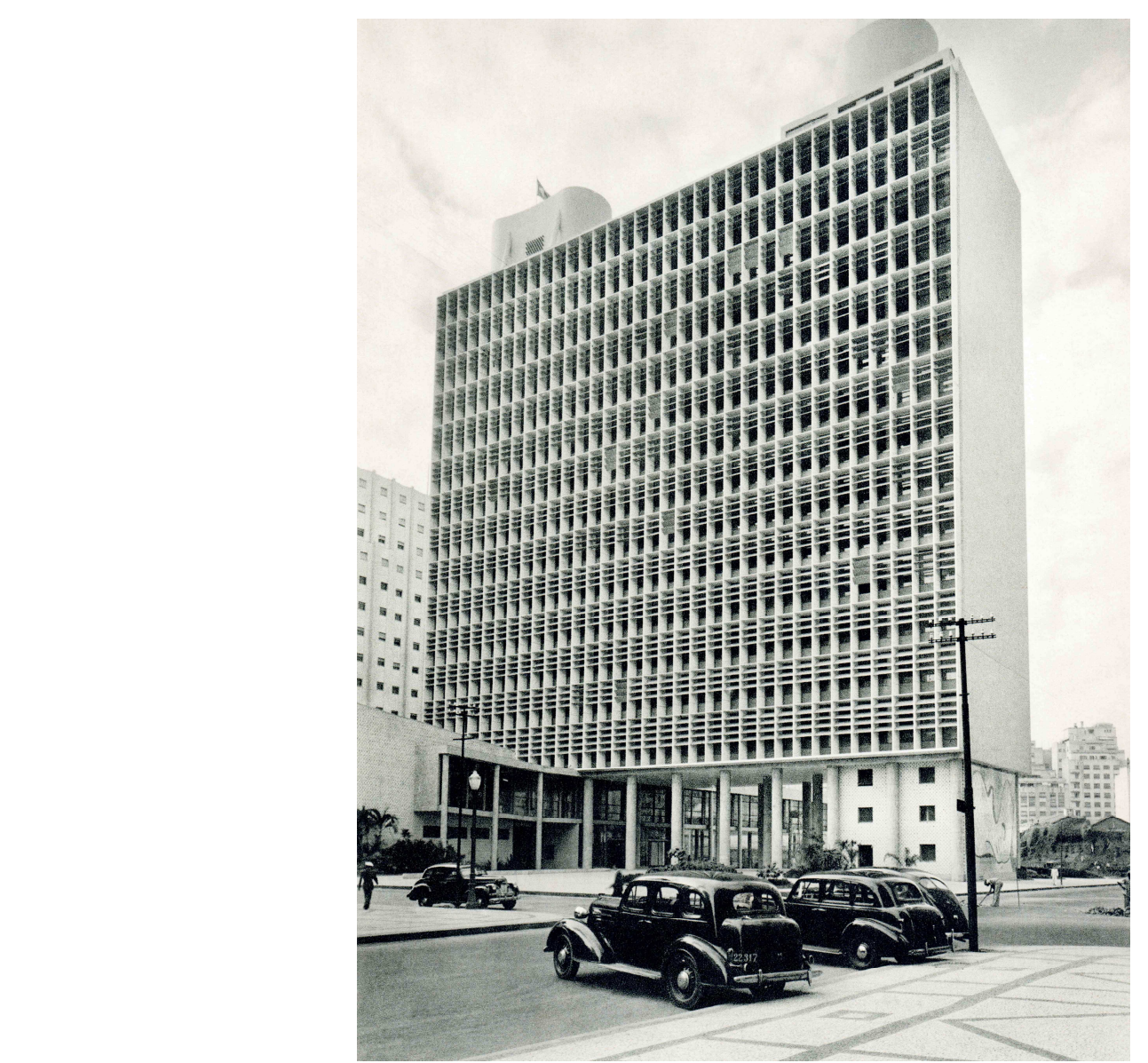

Figura 6: Edifício do MEC, Rio de Janeiro, 1945. Projeto de Lucio Costa e equipe, com consultoria de Le Corbusier, Foto: Arno Kikoler

Fonte: http://jornalriocarioca.com/jornal/?p=11404

Neste sentido, são centrais o estudo das exposições realizadas na década de 1940 pelo MoMA de Nova Iorque, principalmente "Brazil Builds", "Latin American Architecture since 1945" e "Built in USA" e os respectivos catálogos, conforme proposto por Carlos Eduardo Comas em sua tese de doutorado. Tais iniciativas não podem ser vistas com ingenuidade, mas como parte da agenda do Pan-americanismo e da política de "boa vizinhança" conduzida por Roosevelt junto à América Latina. 
O bom entendimento da circulação de tais teorias e seus desdobramentos no campo da arquitetura e do urbanismo ocidentais são fundamentais para compreender o período de transição em que a influência europeia na América Latina cede lugar à dominação cultural estadunidense e é reforçada a partir do segundo pós-guerra. A relação entre esta ideia e os interesses econômicos envolvidos no estabelecimento de tal relação de vizinhança é bem representado pela frase de Manfredo Tafuri no livro "De la vanguardia a la metropoli", em citação de Adrian Gorelik:

Liberar-se do medo do futuro, fixando esse futuro como presente: o fundamento do intervencionismo keynesiano e o das poéticas da arte moderna é o mesmo. (GORELIK, 2005)

O modelo de habitação coletiva de grande escala é parte constituinte das teorias urbanas modernas, em geral de pretensão universalista, fruto da revolução industrial que se inicia no século XVIII e das grandes guerras do XX. Um estudo que pretenda compreender as origens e evolução de tal modelo deve partir daí. 0 entendimento do contexto histórico, social e político em que se deram as realizações em estudo requer a revisão das principais teorias urbanas propostas e aplicadas em diversas partes do mundo ocidental ao menos desde finais do século XIX. O advento das "torres na natureza" em oposição à quadra urbana de Haussmann ou Cerdá, às cidades-jardim de Howard e até mesmo às siedlungen de Ernst May não pode ser plenamente avaliado sem antes compreendermos a dialética entre cidade e campo que caracteriza as tentativas de urbanização desse período e a relação do homem com a natureza na virada do século $X X$.

A explosão urbana do século $X X$ traz consigo uma profunda tranformação na relação até então existente entre a cidade e o campo e entre o homem e a natureza. Se a cidade antiga era tida como espaço seguro onde se abrigar dos perigos da natureza desconhecida do lado de fora, a cidade moderna se estende ao ponto de perder de vista seus limites e assim o contato real com a natureza, rompendo tal relação. Muda então o significado atribuído à natureza, tornada agora espaço desejado de sossego e descanso das angústias e incertezas do homem urbano moderno. As principais alternativas de habitação propostas para a cidade moderna levam em conta este desejo, que dentre muitas gradações, alcança dois extremos: de um lado o anseio de uma residência familiar campestre com seu próprio jardim, afastada do caos urbano; no extremo oposto, a ideia da concentração máxima de moradias mínimas em blocos verticais como estratégia de liberação de grandes áreas verdes de uso público. A cidade-jardim versus a torre na natureza: de um lado o 
retorno ao bucolismo campestre e de outro a organização da vida urbana como modo de ordenar o mundo, como bem colocado por Adrián Gorelik a partir da teoria da Nostalgia e Plano de Manfredo Tafuri:

Nostalgia para ordenar o caos do presente e Plano para neutralizar o medo do futuro: na encruzilhada desses dois impulsos nasce a cultura arquitetônica de vanguarda na década de 1930 na América Latina. Nostalgia e Plano: toda indagação sobre as vanguardas latino-americanas deve encarar o problema de uma cultura arquitetônica cuja configuração moderna reconhece essa origem cruzada, porque ela afeta a própria noção de vanguarda. (...) A vanguarda arquitetônica não só oferecerá seu Plano ao conjunto da vanguarda, como modo de configurar o ordenado mundo moderno que ela imaginava ou pressupunha, mas também introduzirá, por definição, o ator fundamental da renovação vanguardista na América Latina: o Estado, promotor privilegiado daqueles impulsos contraditórios.(...) A partir dos anos trinta essa ambiguidade estatal se espelha na de um modernismo pronto a disputar com os setores tradicionalistas o lugar a partir do qual se construiria uma tradição, produzindo essa paradoxal modernidade de projetar para o futuro o que tencionava resgatar do passado. (GORELIK, 2005)

A influência do desenvolvimento da tecnologia também não deve ser desprezada quando tratamos de grandes edifícios em altura. Destacam-se aí a evolução no conhecimento dos materiais e no cálculo estrutural, em aço ou em concreto, dependendo do local. De modo análogo, é impossível ignorar a importância da invenção do elevador de segurança, apresentado ao mundo por Elisha Otis na Exposição Mundial de Nova Iorque em 1853 e sem o qual a verticalização das construções não teria sido possível.

$\mathrm{Na}$ era das escadas, todos os pavimentos acima do segundo eram considerados inadequados para uso comercial e todo acima do quinto, inabitáves. Desde 1870 em Manhattan, o elevador tem sido o grande emancipador de todas as superfícies horizontais acima do solo. O aparato de Otis recupera todos os incontáveis planos que estiveram flutuando no fino ar da especulação e revelam sua superioridade em um paradoxo metropolitano: quanto maior a distância da terra, maior o contato com o que ainda resta da natureza (i.e., luz e ar). O elevador é a suprema profecia auto-realizada: quanto mais ele sobe, mais circunstâncias indesejáveis deixa para trás. Estabelece também uma relação direta entre repetição e qualidade arquitetônica: quanto maior o número de pisos empilhados ao redor do fosso, mais eles se fundem em uma forma única. O elevador produz a primeira expressão estética baseada na ausência de articulação. Em 1880 o elevador conhece a estrutura metálica, apta a suportar os territórios recémdescobertos sem ocupar muito espaço. Através do apoio mútuo destas duas revoluções, qualquer terreno agora pode ser multiplicado ad infinitum para produzir a proliferação de área de piso chamada arranha-céu. (KOOLHAAS, 1994) 


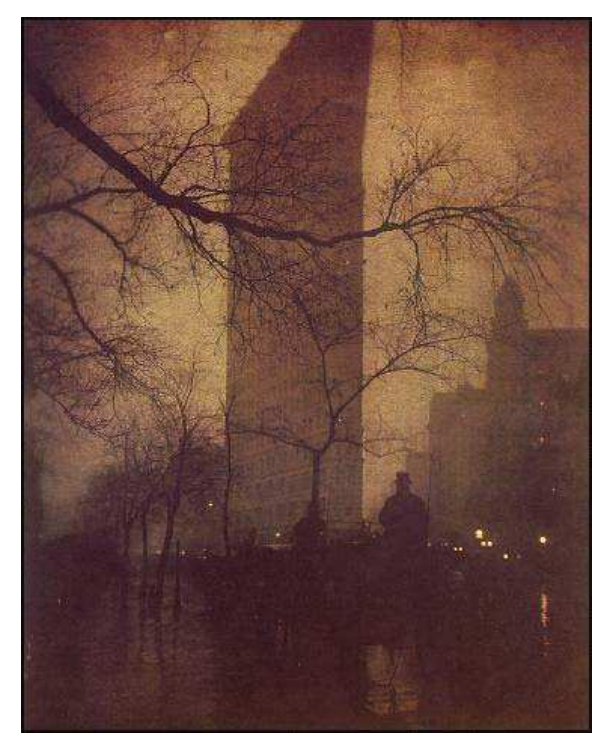

Figura 7: Edifício Flatiron, Nova York, 1904, por Edward Steichen

Fonte: http://en.wikipedia.org/wiki/File:Steichen_flatiron.jpg

É então não pelo caminho da ideologia, mas a partir de uma "vanguarda de Estado" no contexto da reestruturação produtiva e da noção estadunidense de multiplicação do solo urbano que o modelo de habitação vertical em grande blocos desembarca na América Latina, no desvio do "centro do mundo" da Europa para os EUA após 1945.

O tema da habitação vertical de grande escala na América Latina carece ainda de entendimento. Tratado tangencialmente em pesquisas com foco na habitação social, no movimento moderno ou em estudos puramente sociológicos, falta ainda abordar os aspectos propriamente arquitetônicos, tipológicos, urbanos e tecnológicos da questão e os novos aportes ao tema realizados em seu trasladamento à "periferia".

Ao contrário de justificar o recorte da pesquisa pelo viés da "habitação de interesse social", considera-se mais rica a possibilidade de averiguar o modo de produção adotado em cada caso e a partir disso, tentar identificar suas eventuais consequências. De modo semelhante, o recorte a partir da densidade edificada foi descartado, uma vez que a implantação de grandes blocos em terrenos muito grandes resultam em baixas densidades, prejudicando assim sua utilização como parâmetro de seleção. Sem embargo, por tratar-se de questão cada vez mais central dentro das discussões atuais de dinamização do espaço urbano contemporâneo, o fator densidade, aliado ao sinecismo que busca-se aliar a ele, será analisado caso a caso e tratado como aspecto primordial da questão em estudo. 


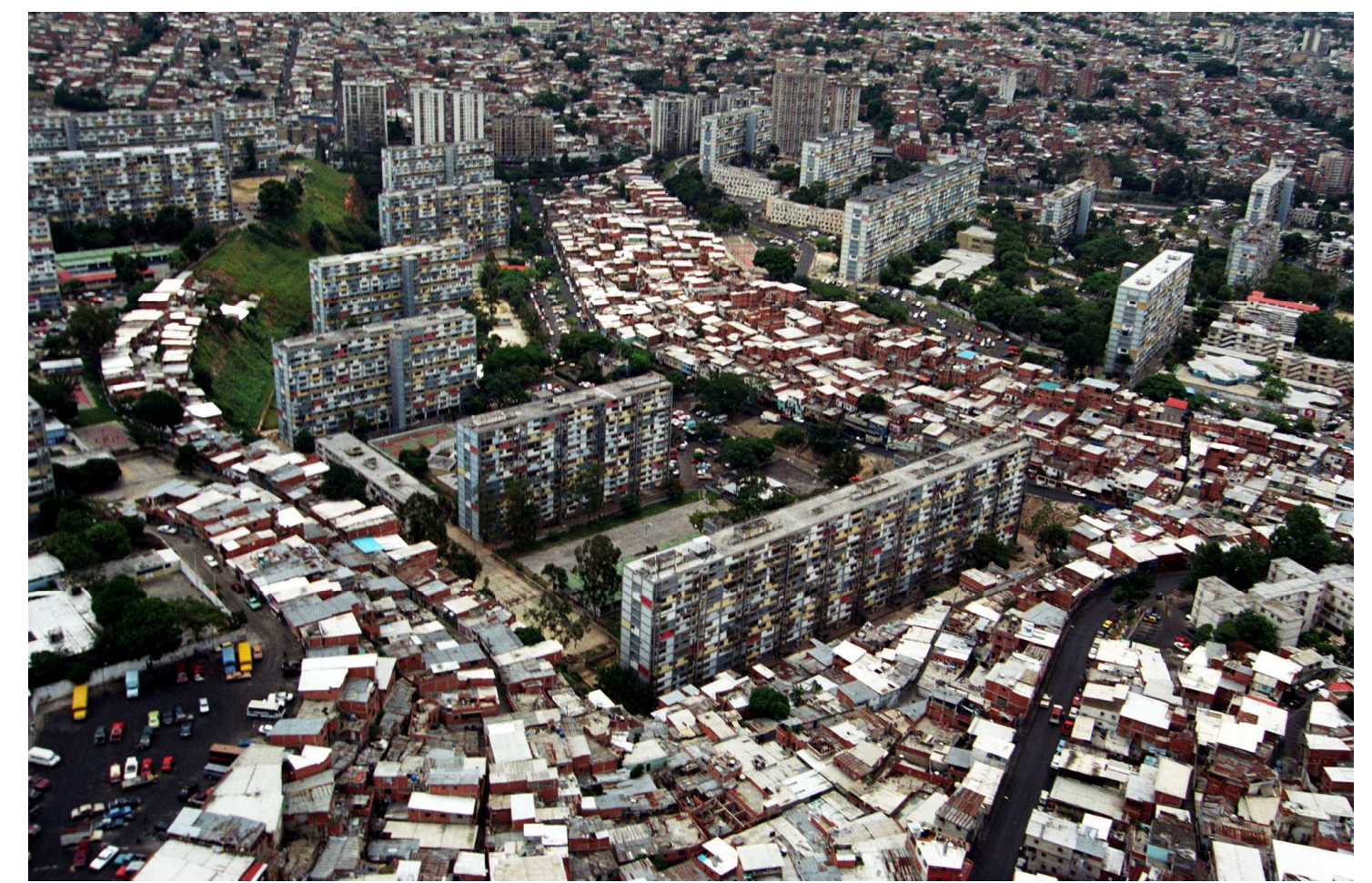

Figura 8: Urbanización 23 Enero. Projeto de Carlos Raúl Villanueva, Carlos Celis Cepero e equipe.

Fonte: http://alexandravocht.files.wordpress.com/2012/10/caracas-23-de-enero.jpg

\section{Alguns fatores que envolvem o tema em estudo}

As discussões acerca dos fatores positivos do incremento da densidade urbana em áreas centrais e dos benefícios trazidos pela presença de usos múltiplos em áreas urbanas vem sendo discutida já há algum tempo, por autores e enfoques bastante distintos. Na América Latina a revalorização do tema é relativamente recente e aponta a necessidade de estudar as condições atuais da moradia urbana nas grandes cidades do continente, entendendo que a habitação é o elemento responsável por amalgamar a cidade e constitui, em última instância, a maior parte de sua massa construída. A presente pesquisa busca, especificamente, um maior entendimento da habitação vertical de grande escala na América Latina, a partir da documentação e análise de algumas obras marcantes, selecionadas a partir de recorte tipológico, como se verá adiante. A relevância do estudo do presente tema vem sendo apontada por diversos autores e aponta tanto para um desenvolvimento e aprofundamento das primeiras postulações habitacionais pelos pioneiros modernos europeus quanto para as transformações da cidade latino-americana observadas a partir da metade do século $\mathrm{XX}$, como colocado por Carlos Sambricio:

A reconstrução, após a [primeira] guerra, eliminou a situação anterior: se os debates entre profissionais se mantiveram, após os confrontos cada país adotou uma política própria, descartando ou ignorando as pautas 
estabelecidas por aqueles que poucos anos antes eram seus oráculos. De algum modo se fechava um ciclo. No entanto a continuidade com o debatido nos anos trinta na Europa não se daria neste continente, mas na América Latina. [...] embora as políticas desenvolvidas na Argentina, Chile, Brasil, Cuba, Venezuela, Colômbia e México tenham sido estranhas e distintas entre si, o modo de enfrentar a construção de habitações para a classe média - a preocupação com a célula ou a definição de edifícios em altura - e a transformação da cidade se deu de maneira similar, o que aponta a necessidade de reivindicar estudos comparativos de cada um dos aspectos acima mencionados. (SAMBRICIO: 2013, pp. 8-9)

A partir de certas dimensões, o edifício de habitação coletiva promove relações bastante distintas daquelas envolvidas em edifícios de menor escala. A aglomeração de centenas ou até mesmo milhares de unidades de moradia, organizadas em altura em grandes blocos, isolados ou em conjunto, suscitam questões além da simples articulação arquitetônica de elementos mais ou menos semelhantes entre si. $O$ aumento de escala e complexidade do conjunto incorpora ao edifício situações que aproximam-se daquelas presentes no próprio espaço urbano, hipótese reforçada por Rodrigo Antoncic:

Não obstante as tensões entre unidade e conjunto, privacidade e coletivo, o edifício de apartamentos segue sendo a opção mais plena de vida na cidade, da qual incorpora não poucos de seus conflitos e contradições. É aí que reside o seu interesse e atualidade. (ANTONCIC: 2012, p. 37)

O benefício principal da habitação vertical de grande escala é bastante óbvio: a densidade. A possibilidade de abrigar mil famílias num mesmo terreno que acomodaria não mais que 50 casas em terrenos isolados é um potencial que não deve ser desprezado, principalmente se levada em conta a crescente elevação dos valores da terra urbana. No entanto, para avaliar sua possível adoção nos dias de hoje, devese antes considerar como o impacto da inserção de edifícios de tais dimensões em dado contexto urbano pode se dar de modo positivo e ainda se os usos a serem ali introduzidos são compatíveis com o local. Somente a partir da análise ponderada e criteriosa de fatores como estes pode-se decidir acerca da pertinência ou não da adoção de tal tipologia de construções, o que nem sempre foi feito quando da construção de edifícios deste porte nas cidades latino-americanas a partir da metade do século $X X$.

\section{Mapeamento e identificação dos edifícios em estudo}


O impacto da inserção de um grande bloco habitacional em um dado local e o grau de inter-relação com o entorno criados aí podem ser de tal complexidade que uma análise criteriosa e atenta ao contexto urbano específico se impõe, conforme sugerido por Philippe Panerai:

O estudo da relação entre os tipos construídos e a forma urbana é 'o meio para compreender a estrutura da cidade ao mesmo tempo como continuidade histórica de um processo e como fenômeno parcial de tal continuidade'; ele não constitui um fim em si mesmo e deve ser acompanhado por uma análise dos 'elementos da estrutura urbana' e dos 'processos de crescimento'. [...] Porém, o que conta não é a simultaneidade dos fenômenos, mas a semelhança em sua sucessão. Segundo Aymonino, é possível definir as características gerais das cidades ocidentais sabendo-se que rapidamente 0 fenômeno se difunde e tende a ser análogo em todas as cidades onde se manifesta.(PANERAI: 1999, p. 124-127)

O autor vai além, defendendo um conceito dinâmico de tipo como instrumento operativo e não como uma determinante preestabelecida, apontando todavia indicações gerais para subsidiar a caracterização ou construção de uma tipologia a ser analisada:

Ferramenta de trabalho, não é necessário ater-se a uma definição única da tipologia, mas a constantes redefinições em função das pesquisas'. [...] Nesse sentido, distinguiremos quatro fases: a definição da abrangência [divididos em 'escolha de níveis' e determinação da área de estudo']; a classificação prévia; a elaboração dos tipos; a tipologia. (PANERAI: 1999, p. 124-127)

A caracterização tipológica que embasa o recorte da pesquisa parte do Método da Análise Tipológica proposto por Panerai no livro Análise Urbana. No capítulo Tipologia, Panerai analisa a evolução do conceito de tipo, partindo de sua origem nas ciências biológicas, sua definição em arquitetura por Quatremère de Quincy, sua adoção e desenvolvimento por J. N. L. Durand até sua atualização por Carlo Aymonino e Saverio Muratori, onde a compreensão do tipo só é possível como parte dos fenômenos urbanos. Aplicando tais definições à presente pesquisa, alcança-se o seguinte resultado:

- Abrangência de nível: Habitação coletiva vertical de grande escala;

- Abrangência geográfica e temporal: América Latina, século XX;

- Classificação prévia: os parâmetros de recorte estabelecidos para a pesquisa são:

- articulação vertical dependente do elevador;

- potencial para abrigar ao menos uma centena de famílias; 
- configurar-se como bloco isolado (não construído lado a lado ao modo das cidades tradicionais);

- possuir representatividade e intencionalidade do ponto de vista arquitetônico.

- $\quad$ Elaboração dos tipos: ver seleção de obras listada abaixo

- A tipologia: De modo geral, corresponde ao modelo de bloco isolado de grande escala, postulado a partir da década de 1920 em busca por solução adequada de habitação urbana visando a concentração vertical de um grande número de moradias com vistas a liberação do solo. Representa oposição à quadra tradicional da cidade europeia, conforme proposto por Le Corbusier no livro "Maneira de pensar o urbanismo" (fig. 9) e cuja evolução é descrita de modo preciso por Panerai em "De L'ilot a la barre".
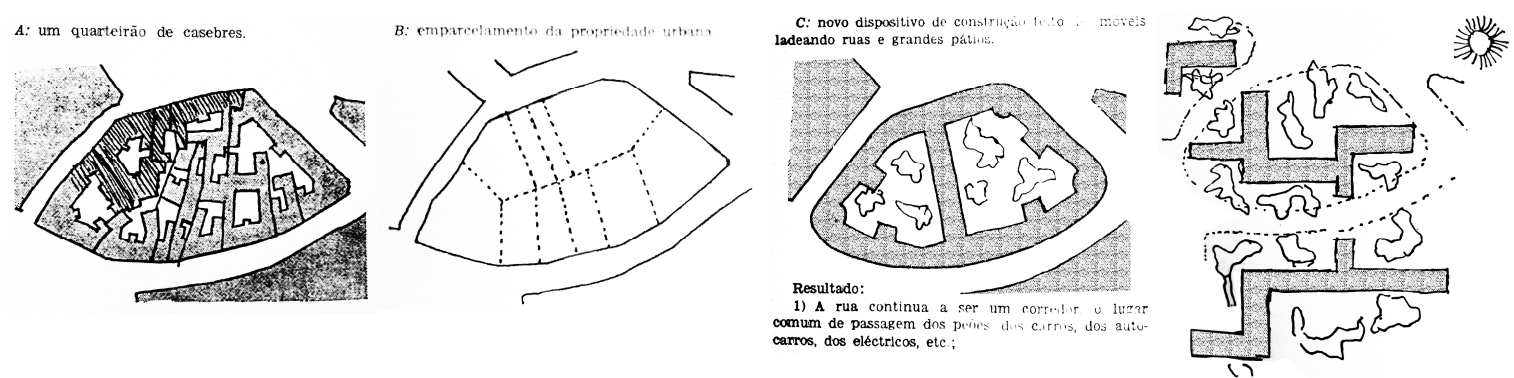

Figura 9: Evolução da quadra tradicional ao bloco isolado apresentada por Le Corbusier (LE CORBUSIER: Maneira de pensar o urbanismo, 1946)

A partir dos parâmetros assim estabelecidos, procurou-se selecionar em cada cidade ou país ao menos um exemplo da aplicação direta das diretrizes originais modernas e também um ou mais casos que apresentem novo aporte no desenvolvimento da tipologia em estudo. Acredita-se assim que, ao serem tratados comparativamente, o número de exemplos e a abrangência geográfica adotada possam atribuir à pesquisa uma representatividade considerável para uma avaliação concreta das condições atuais de tais edifícios e de sua pertinência nos contextos urbanos das metrópoles latino-americanas atuais. A partir desse recorte, os edifícios que constituem o objeto central da pesquisa são:

Tabela 1 - Dados básicos acerca dos edifícios selecionados para o estudo de casos

PAÍS

BRASIL

\section{CIDADE}

$$
\text { Belo Horizonte Conjunto Governador Kubitschek (1951 -1970) Oscar }
$$$$
\text { Niemeyer }
$$

Rio de Janeiro Conjunto dos Jornalistas (circa 1954) Autoria ?

Centro da Barra (1969 - 1994) Oscar Niemeyer 
São Paulo Edifício Japurá (1945 - 1957) Eduardo Kneese de Mello Edifício Copan (1951 - 1966) Oscar Niemeyer Edifício Viadutos (1951 - 1955) Artacho Jurado Conjunto Nacional (1952 - 1956) David Libeskind Conj. Nações Unidas (1953 - 1964) Abelardo de Souza

ARGENTINA Buenos Aires El Hogar Obrero (1950 - 1955) Fermín Bereterbide e Wladimiro Acosta

Complejo Rioja (1969 - 1973) Rafael Viñoly e equipe

VENEZUELA

MÉXICO

CUBA

COLÔMBIA

URUGUAI

CHILE
Caracas Unidad Residencial "El Paraíso" (1952-1954) Carlos Raúl Villanueva e C. Celis Cepero

Unidad Residencial Cerro Grande (1951-1954) Guido Bermúdez

Unidad Residencial 23 Enero (1952-1954) Carlos Raúl Villanueva e equipe

Torres del Parque Central (1969-1983) Daniel FernandesShaw

Cidade do Centro Urbano Presidente Alemán (1949-1950) Mario México Pani e equipe

Unidad Residencial Tlatlelolco (1949-1964) Mario Pani e equipe

Havana Edifício FOCSA (1953 -1956) Ernesto Gomez-Sampera e equipe

Unidad Vecinal No. 1 (1959 -1962) Mario González, Hugo Dacosta, Mercedes Álvarez, Reynaldo Estévez, Eduardo Rodríguez e Lenin Castro

Bogotá Centro Urbano Antonio Nariño (1951 -1970) Nestor Gutiérrez e equipe

Torres Del Parque (1966 -1970) Rogelio Salmona

Montevideo Edificio La Ciudadela (1958 -1960) Raúl Sichero Bouret

Edifício Panamericano (1960 -1964) Raúl Sichero Bouret

Complejo Bulevar Artigas (1971 -1973) Ramiro Bascans, Thomas Sprechmann, Arturo Villamil, Hector Vigliecca

Santiago Edifício Plaza de Armas (1953 -1958) Sergio Larrain García-Moreno, Emilio Duhart, Jaime Larrain Valdés, Jaime S. Yrarrázaval, Osvaldo Larraín Echeverría,

Residencial Torres de Tajamar (1960 -1964) Bresciani, Valdés, Castillo y Huidobro com Luis Prieto Vial

Unidad Vecinal Providencia (1953 -1968) Carlos Barella 
Iriarte e Isaac Eskenazi Tchimino

Remodelación Republica (1962 -1969) Vicente B. Camus, Víctor C. Barros, Jaime P. Ide, Orlando S. Mellado

PERU

Lima Conjunto Habitacional San Felipe

(1a Etapa - 1962-1966) Enrique Ciriani

(2a Etapa - 1965 -?) Jacques Crousse, Jorge Páes, Víctor

Smirnoff, Vásquez, Javier Velarde, entre outros.

Muitas vezes distintas das postulações originais europeias, as realizações latino-americanas possuem características originais e várias delas apresentam aportes consideráveis na relação que estabelecem com as cidades. Ao serem implantadas no interior das quadrículas urbanas preexistentes, não necessariamente rompem o espaço da rua-corredor, a qual Le Corbusier tanto abominava e propunha destruir e em muitos dos casos, resultam em espaços urbanamente ricos e cheios de vivacidade. Naturalmente, existem exemplos em ambos os sentidos, e parece ser justamente na identificação dos benefícios e problemas fruto da adoção de um ou outro modelo, em situações distintas, que reside a compreensão dos fatores em jogo.

Um olhar em perspectiva lançado sobre tais edifícios permite também perceber, retrospectivamente, como muitos deles efetivamente tiveram papel determinante na configuração das metrópoles latino-americanas como hoje são e, ao menos em parte, explicam a escala vertical que hoje caracteriza muitas delas. Neste sentido, José Rosas propõe que:

A identificação da habitação como elemento constitutivo do processo de configuração e consolidação do centro da cidade, dos valores de centralidade geradores da vida urbana e da vitalidade do sistema urbano que esta atividade promove, viria confirmar não apenas um processo contínuo de agregação de tipos edificados com dito uso, mas também exige aceitar a residência central, sem renunciar aos princípios modernos nem evitar as fortes densidades introduzidas pela altura, continuando uma busca por maior coesão com o tecido urbano. [...]

As propostas de habitação centrais que se agregam à quadrícula na América Latina manifestarão, contrariamente à independência que exibirá a habitação na periferia, fortes relações com o processo moderno de reurbanização do centro. Estas propostas também apresentam uma interessante dialética sobre o traçado existente, que, como ocorre com o aumento da altura, revelarão novas possibilidades de interpretar a estrutura urbana existente. [...]

Haveria que valorizar de um modo profundo a formação destes novos conceitos de tipologia edificada, cujas características permitiram, por um lado, uma modificação substantiva do padrão histórico com que majoritariamente se construiu a cidade durante séculos. Por outro lado, devido a sua correspondência com a morfologia urbana, permitiu visualizar que o novo papel que o centro original da cidade alcança neste período, é em boa parte 
devido ao papel que a atividade residencial teve nas previsões de novas edificações na cidade moderna.[...] Cabe reconhecer também, que a própria tradição urbanística do movimento moderno privilegiou uma visão predominantemente suburbana de desenvolvimentos residenciais rumo às periferias. Estes desenvolveram-se sob o esquema de "cidade jardim", com uma clara diferenciação tipológica dos edifícios de habitação no novo esquema de cidade funcional. (ROSAS: 2009, pp. 18-20)

Deste modo, percebe-se que a pesquisa tipológica envolvendo novos modelos de habitação na América Latina, muito embora inicialmente inspirada pelas experiências seminais de figuras como Le Corbusier, Walter Gropius e Ernst May, é fundamentalmente distinta daquela realizada no pós-guerra europeu. Distintos também são, entre si, os próprios edifícios objeto desta pesquisa, e tratá-los como se iguais fossem implicaria num reducionismo metodológico inaceitável para uma abordagem científica do tema em questão. Acredita-se que a análise comparativa de tais edifícios, tendo em vista suas diferenças e semelhanças, tem o potencial de lançar alguma luz à questão e contribuir para a ampliação e atualização do tema, como ratificado por Florian Urban:

A comparação de projetos aparentemente similares [em diferentes contextos] sugere que o triunfo ou fiasco não depende de uma única variável mas sim de uma fórmula complexa que inclui não somente a forma ou o programa, mas também sua composição social, a posição dentro da cidade, manutenção efetiva e uma variedade de indicadores culturais, sociais e políticos. Se apenas um destes fatores for negligenciado, toda a iniciativa estará ameaçada, e o que poderia ser um símbolo de conforto e boa habitação pode facilmente tornar-se uma epítome de miséria e privação. (URBAN: 2012)

\section{Crítica global e assimilação local}

As críticas ao modelo de habitação em estudo, promovidas a partir dos anos de 1960 e 1970, foram impiedosas, embora sua importação para a América Latina tenha sido geralmente acrítica. As repercussões da crítica pós-moderna europeia e norte-americana nos países latino-americanos foram intensas e, a despeito da validade ou não dos experimentos aqui realizados, levou praticamente ao abandono de tal modelo, até os dias atuais. Tão rápido quanto foram adotados por todo o continente, os edifícios de habitação vertical de grande escala foram também proscritos, sem que a devida avaliação de suas consequências e suas condições atuais fossem avaliadas pragmaticamente.

É importante notar que, no momento atual, enquanto a habitação de grande escala volta a ser questionada na Europa e em Londres cogita-se a demolição dos 
Robin Hood Gardens dos irmãos Smithson, no Brasil os conjuntos Pedregulho, COPAN e JK passam por processos de restauração e revalorização pela população, bem como outros residenciais do mesmo porte. Na Colômbia, o Centro Urbano Antonio Nariño e as Torres do Parque vão muito bem, obrigado. No Chile, as Torres de Tajamar, o Conjunto Providência e a Remodelación República são hoje totalmente integrados ao contexto urbano e não apresentam grandes problemas, contribuindo para a manutenção de zonas urbanas vivas e seguras de Santiago. Os conjuntos de Mario Pani no México passam por processo semelhante e mesmo em Caracas, embora os conjuntos do Banco Obrero, em especial 23 Enero e Cerro Grande sejam casos especialmente delicados, o complexo das Torres do Parque Central de Fernández-Shaw - projeto criticado severamente quando de sua implantação - segue sendo um dos núcleos de comércio e serviços mais vivos da área central da capital venezuelana. Mesmo em Nova York, os housing projects de Sert em Roosevelt Island são hoje considerados locais desejáveis e valorizados de moradia urbana.

O momento atual, no contexto digital e hiperconectado do século XXI, parece requerer uma atualização das críticas do período pós-moderno, muitas delas precoces, superficiais e não raro baseadas mais em ironias que em argumentos concretos. Há por trás de muitas delas agendas ocultas - ou nem tão ocultas - cujo objetivo estava mais em vencer disputas internas ao campo da arquitetura, centradas em questões estilísticas, que efetivamente discutir modelos adequados para a moradia urbana e a melhoria das cidades. Se as teorias de Jane Jacobs ou Henri Lefebvre parecem manter-se atuais, as críticas sessentistas de Charles Jencks e Tom Wolfe dificilmente podem hoje ser levadas a sério. Separar o joio do trigo é necessário, principalmente tendo em vista que o contexto urbano latino-americano é distinto e quiçá bem mais matizado que o europeu ou mesmo o estadunidense.

\section{Possibilidades para uma reavaliação contemporânea}

Precocemente, já ao final do período em que trabalhou no atelier de Corbusier na Rue de Sévres, na década de 1950, o colombiano Rogelio Salmona discordava da abordagem do mestre às questões urbanas, pressentindo que algo ali poderia não estar correto:

Rogelio Salmona respeitava as propostas e as soluções de Le Corbusier, mas Ihe preocupava especialmente aquelas propostas para a Colômbia, pois as sentia estranhas. Se intranquilizava pelo fato de planejar cidades desde uma 
mesa de desenho, e assim decidir simplesmente sobre a vida das urbes. Nas excursões por cidades que fazia nesta época, estas mostravam-se como corpos vivos, dinâmicos e ricos. As unidades habitacionais e alguns dos projetos em que trabalhava, sentia-os às vezes encaixotados, e Ihe produziam uma mescla de admiração e dúvida. Salmona sentia que para Le Corbusier a cidade era um problema teórico e, ainda que com admiração por seu professor, não podia compartilhar este conceito. (ARISTIZÁBAL: 2006, p. 43)

Torna-se então fundamental para uma análise pertinente de tais edifícios deixar claro que as Torres del Parque de Salmona, em Bogotá, não são o mesmo que o Pruitt-Igoe nem são iguais 23 de Enero em Caracas e Tlatelolco na Cidade do México, embora sejam complexos de porte semelhante. Mesmo dentre os projetos selecionados como objeto da pesquisa em curso, muitas são as diferenças, naturalmente: de contexto, de abordagem projetual, de agrupamento dos edifícios, de relações estabelecidas com o entorno urbano, usos públicos presentes etc.

Tratar da habitação vertical de grande escala como se o simples porte das edificações ou do conjunto edificado fosse responsável por fazê-los todos iguais é ignorar a complexidade deste tipo de arquiteturas, como já mencionado acima. Em sendo assim, é igualmente injustificável o abandono das possibilidades oferecidas pela adoção destes modelos de habitação em virtude da existência de experiências malsucedidas no passado, seja na América Latina ou na Europa. De modo a alargar a discussão, cabe mencionar que há autores, como Xavier Monteys que, ao contrário da ruptura que em geral se atribui ao edifício de habitação de grande escala, propõem sua interpretação como uma evolução tipológica da casa de cômodos, dos palácios ou de hoteis urbanos, centrando sua análise no uso, e não na forma edificada:

Em uma chave distinta e mais próximos no tempo, alguns dos cosmopolitas hotéis de Nova York ou Chicago, nos ajudam a costurar, mais do que fazer evidente um corte, uma coleção de exemplos que necessita novos argumentos que permitam construir um relato mais imaginativo que heroico. Estes hoteis, construídos como palácios urbanos e dotados de todo tipo de serviços são a versão burguesa daqueles palácios para as cortes europeias, opulentos, colossais e soberbos, mas também eficazes. Edifícios nos quais se residia segundo umas normas e nos quais quem os utilizava eram mais hóspedes que viajantes ocasionais. Todos estes edifícios, os palácios europeus, os hoteis americanos ou o familistério, têm em comum serem concebidos como edifícios de quartos dotados de serviços. Suas plantas são o resultado da repetição destes cômodos e da necessidade de garantir seu acesso, tudo realizado com a intenção de que suas condições sejam relativamente equivalentes. (MONTEYS: 2012)

Muitas décadas se passaram desde a construção dos edifícios em estudo e, nesse intervalo de tempo, as cidades onde eles se encontram mudaram muito. Talvez 
mesmo, em alguma medida, como consequência da própria existência destes edifícios, que vieram em alguns locais catalisar a verticalização e a mudança da escala edificada de contextos urbanos inteiros. Sob outro viés, em virtude dos avanços recentes das tecnologias de comunicação, nas últimas décadas mudaram ainda mais a vida das pessoas e com isso sua visão de mundo e sua relação com as cidades e com os espaços construídos. Diante de tudo isso, trabalha-se aqui com a hipótese que, muito embora a implantação dos edifícios em estudo possa sim, ter sido precipitada e levada a cabo sem o devido critério, talvez hoje eles possam fazer mais sentido do que quando foram inaugurados. Paralelamente, é importante considerar que vêm também modificando-se as opiniões acerca da arquitetura moderna como um todo, antes considerada estranha, mas hoje familiar. Neste sentido, Theo Prudon aponta que:

A opinião pública sobre a arquitetura moderna já percorreu um longo caminho desde os dias do escárnio do Boston City Hall e do uso da arquitetura como bode expiatório, quando da decadência do conjunto habitacional Pruitt-Igoe em St. Louis. Com a sua demolição, em 1972, Charles Jencks, quase triunfante, declarou morta a arquitetura moderna. Hoje, com a nossa nostalgia da primeira metade do século XX e toda a onda de Mad Men, PanAm, etc, podemos dizer que este está longe de ser o caso. É realmente irônico que, enquanto o edifício PanAm é revalorizado, o seu terminal no aeroporto JFK, agora usado pela Delta, está programado para ser demolido. $[\ldots]$

Os tempos mudaram e, para contradizer Charles Jencks, a arquitectura moderna está longe de estar morta. Na verdade, o interesse no período está crescendo e, talvez, ao menos desta vez, possamos aprender com nossos erros e construir melhores moradias, que sejam acessíveis, mas também arquitetonicamente inovadoras. (PRUDON: 2011) 


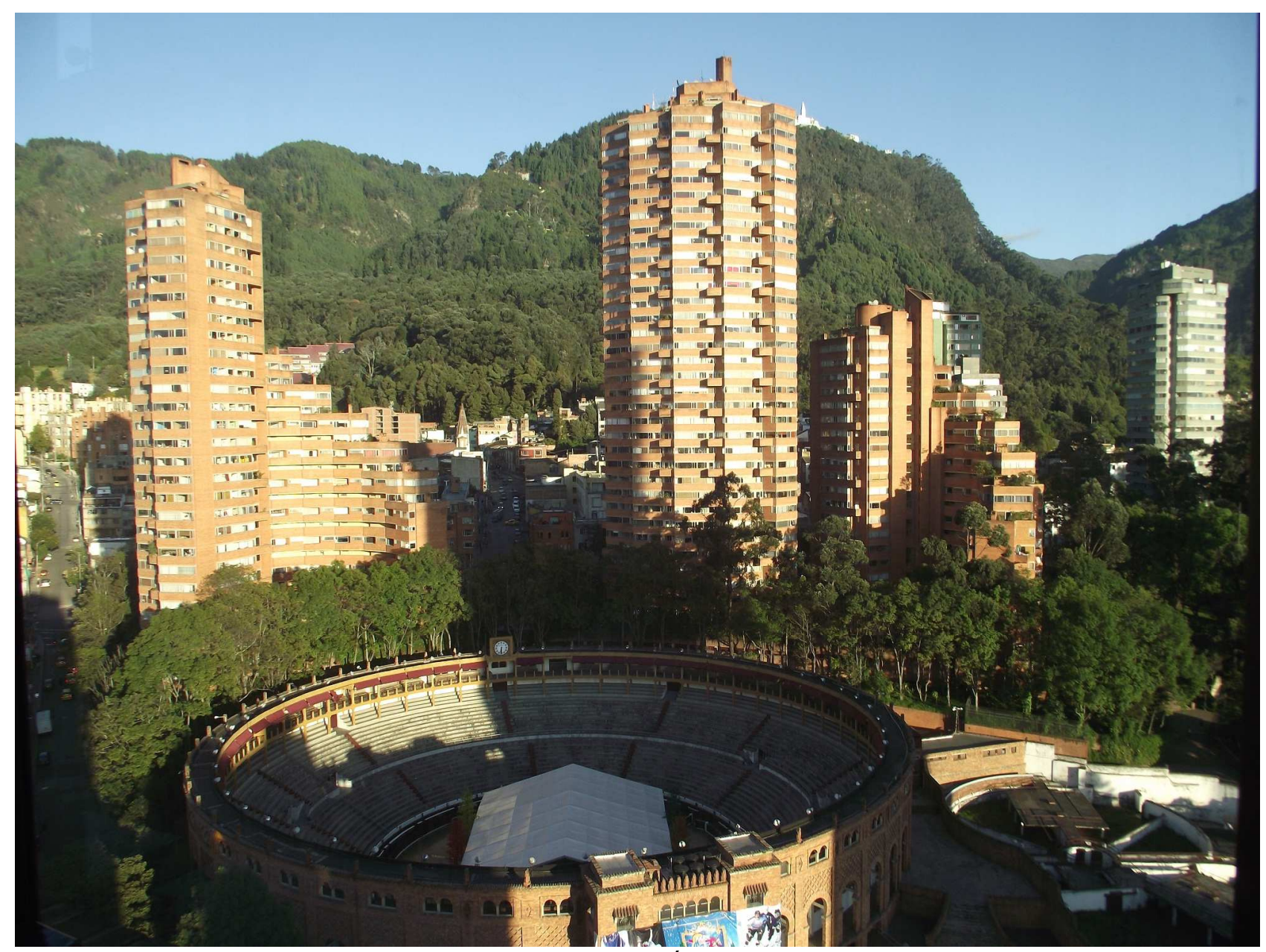

Figura 10: Torres del Parque, Bogotá. Projeto de Rogelio Salmona

Fonte: Foto do autor, Março de 2013

Parafraseando Sir Arthur Clarke, autor da novela que inspirou o filme 2001: Uma Odisséia no Espaço, devemos perceber que, no que tange ao tema aqui abordado, "o futuro não é mais o que costumava ser".

\section{Referências}

ANTONCIC, Rodrigo Pérez de Arce. Domicilio Urbano. Santiago: Ediciones ARQ, 2012. ARISTIZÁBAL, Nora. Rogelio Salmona: Maestro de Arquitectura. Bogotá: Panamericana Editorial, 2006.

GOMES, Marco Aurélio A. de Filgueiras (org.). Urbanismo na América do Sul: circulação de ideias e constituição do campo 1920-1960. Salvador: EDUFBA, 2009.

GORELIK, Adrián. Das Vanguardas a Brasília: Cultura Urbana e Arquitetura na América Latina. Belo Horizonte: Editora UFMG, 2005. 
HILBERSEIMER, Ludwig. La Arquitectura de La Gran Ciudad. 1a Edição. Barcelona: Editorial Gustavo Gili, 1979.

HILBERSEIMER, Ludwig. Un'idea di piano. 2a Edição. quaderni di architettura e urbanistica polis n. 2. Padova: Marsilio Editori, 1970.

JACOBS, Jane. The Death and Life of Great American Cities. New York: Vintage Books, 1992 [1961]

JACOBS, Jane. The Economy of Cities. New York: Vintage Books, 1970 [1969]

KOOLHAAS, Rem. Delirious New York: A Retroactive Manifesto for Manhattan. New York: Monacelli, 1994.

KOPP, Anatole. Quando o moderno não era um estilo e sim uma causa. São Paulo: Nobel, 1990.

LE CORBUSIER. Maneira de Pensar o Urbanismo. Lisboa: Europa-América, 1977 [1946]

LEME, Ma. Cristina da Silva (org). Urbanismo no Brasil 1895-1965. São Paulo: Nobel, 1999.

MONNIER, Gerard. Le Corbusier: Les unités d'habitation em France. Paris: Éditions Belin, 2002.

MONTEYS, Xavier. De la casa urbana. In: ANTONCIC, Rodrigo Pérez de Arce. Domicilio Urbano. Santiago: Ediciones ARQ, 2012.

PANERAI, Philippe. Análise Urbana. Brasília: Editora UNB, 2006 (1a edição 1999).

PANERAI, Philippe; CASTEX, Jean; DEPAULE, Jean-Charles. Formes urbaines: de I'îlot à la barre. Paris: Dunod, 1977.

PRUDON, Theodore H. M. Docomomo's Theodore Prudon goes to Roosevelt Island as part of National Tour Day where the lessons in quality housing are more resonant than ever. http://archpaper.com/ news/articles.asp?id=5676. Visitado em 20 de abril de 2014.

ROSAS, José. La vivienda moderna em el centro de Santiago. In: TÉLLEZ, Andrés (org.). Vivienda Multifamiliar em Santiago 1930-1970. Santiago: Pontificia Universidad Catolica de Chile / Universidad Diego Portales, 2009.

SAMBRICIO, Carlos (ed.). Ciudad y Vivienda en América Latina 1930-1960. Madrid: Lampreave, 2013.

TAFURI, Manfredo. Projecto e Utopia: Arquitetura e Desenvolvimento do Capitalismo. Lisboa: Presença, 1985. [1973]

URBAN, Florian. Tower and Slab: Histories of global mass housing. New York: Routledge, 2012 